\title{
Economic and Children's Subjective Well-Being Indicators at the National Level in 35 Countries
}

\author{
Ferran Casas $^{1} \cdot$ Mònica González-Carrasco $^{1}$ D $\cdot$ Xavier Oriol $^{2} \cdot$ Sara Malo $^{2}$
}

Accepted: 23 January 2022 / Published online: 4 March 2022

(c) The Author(s) 2022

\begin{abstract}
This study uses representative samples of 10- and 12-year-olds from the third wave of the Children's Words international survey $(\mathrm{N}=48,499$ 10-year-olds from 35 countries, and $\mathrm{N}=44,692$ 12-year-olds from 30 countries) to explore the relationship between four main economic indicators at the country level and a selection of children's subjective well-being (SWB) indicators. The economic indicators included measures of wealth and wealth inequality, while the SWB indicators included general cognitive and affective indicators of the components of SWB and a selection of satisfaction items with specific life domains or aspects of children's lives. Separated systematic linear regressions were calculated for each age group - each economic indicator being regressed on each SWB general indicator and on each of the selected satisfaction items. As is the case with previous research, the results do not display significant associations between economic indicators and cognitive SWB when using children's data at the population level. In contrast, associations were identified between economic and affective indicators, and between the former and the correlation between affective and cognitive SWB at the country level. These results suggest that the affective and cognitive components of children's SWB display idiosyncratic associations with both wealth and inequality indicators at this level, and that it is very important to analyse SWB components separately. This study also shows that satisfaction with some specific life domains (e.g.: with life as a student, time use or the freedom the child has) may display associations with some economic indicators at the macro level, while satisfaction with other life domains may not, meaning that overall life satisfaction may offer different associations with economic indicators, depending on children's satisfaction with various life domains in each country. These associations may change with age in some cases. Findings contribute to questioning the hitherto widespread belief that a country's macro-economic situation has little or no impact on children's well-being and invite the use of children's SWB indicators from a quadripartite conceptionincluding overall satisfaction with life and life domains, positive affect and negative affect - to monitor the implementation of public policies aimed at children.
\end{abstract}

Extended author information available on the last page of the article 
Keywords Subjective well-being $\cdot$ Children $\cdot$ Economic indicators $\cdot$ Satisfaction with life domains $\cdot$ Inequality $\cdot$ Age $\cdot$ Children's worlds

\section{Introduction}

Children's well-being has traditionally been considered to be influenced by objective (material) and subjective indicators (perceptions and evaluations regarding one's life) operating at both the microsocial and macrosocial level (Land, Lamb, \& Fu, 2015). With regard to the latter, there has been scarce scientific interest in determining whether economic variables have the same influence in children's lives as adults', particularly in contrast with the considerable attention that has been devoted to studying subjective well-being in the adult population (see, for example, the work by Diener and Oishi, 2000).

The lack of international databases including these issues and use of diverse indicators by different studies has prevented any progress being made in research on children in this respect, with a subsequent lack of empirical knowledge regarding the extent to which the economic situation and economic policies might affect children's lives from their own perspective. In other words, identifying how children's material disadvantage relates to SWB may help improve child policies (Gross-Manos, 2017) and even public health monitoring at these ages (Levin et al. 2011).

The present study forms part of this ongoing debate, since it provides an analysis of new data that allows a more comprehensive approach to be adopted to the potential relationships existing between objective - economic variables, in this case - and subjective indicators of children's well-being. The latter are considered in terms of a quadripartite model of SWB, including overall satisfaction with life and life domains, positive affect and negative affect (Savahl, Casas, \& Adams, 2021). This is followed by a summary of the most noteworthy results published on the central elements of this debate to date.

Using a sample of 12,077 12-year-old children from 11 countries in the first wave of the Children's Worlds (ChW; www.isciweb.org) international project, Lee and Yoo (2015) found that the economic variables of GDP (Gross Domestic Product per capita) and inequality (Gini coefficient, a measure of statistical dispersion intended to represent the income inequality or wealth inequality within a nation or any other group of people) were not significant factors in predicting children's subjective wellbeing (SWB) - that is, how children perceive and evaluate their lives globally and for different life domains. These authors used the General Domain Satisfaction Index (GDSI, Casas et al., 2013) as an indicator of SWB, which includes cognitive domainbased SWB scales such as the PWI-SC (Cummins \& Lau, 2005) and the BMSLSS (Seligson et al., 2003).

In the study conducted by Main et al. (2019), the authors were not able to identify any relationship between these two same economic indicators and an indicator of children's cognitive subjective well-being (the PWI-SC) at the national level in a sample of 35,417 children from 15 countries, aged 10 and 12, using the Children's Worlds second wave international database. This, despite the authors acknowledging 
that national wealth is associated with country variations in SWB for adults, as shown in Helliwell, Layard and Sachs (2015), for example.

In a similar vein, Levin et al. (2011) studied the HBSC 2006 dataset of 13-year-olds from 35 countries and found that the GDP (PPP US\$) and the Gini coefficient did not explain between-country variance in socioeconomic inequalities in life satisfaction.

Prior to that, Bradshaw and Richardson (2009) reported moderate positive associations between children's well-being in different age groups and GDP per capita using data from 29 European countries. However, this study did not include a separate analysis with only SWB indicators - the well-being index including both objective and subjective indicators. A subsequent study conducted by Bradshaw and Rees (2017) using the data from 10 and 12-year-ols age-groups of the second wave of the Children's Worlds survey found that economic factors like deprivation can explain variations in children's life satisfaction, although such influences vary considerably between countries. Specifically, they observed that deprivation has a greater impact on the life satisfaction of children in poorer countries. However, although this study took into account the cognitive subjective component of SWB, it did not consider the affective component. Another interesting conclusion of this study was that notable variations are found in the importance of different life domains in children's life satisfaction across countries.

Casas, Oriol and González-Carrasco (2020) also found non-significant correlations between economic indicators (UN GDP nominal per capita and Mean Wealth per Adult in US dollars) and two SWB-related indicators (Positive Affect -PA- and a single-item cognitive scale on life satisfaction, the OLS) using representative samples from 18 countries from the second wave of the Children's Worlds international project ( $\mathrm{N}=41,599,10$ and 12-year-olds groups). However, these authors contributed the surprising result that both economic indicators displayed a significant association with the correlation between PA and the OLS, which is to say, between affective and cognitive components of SWB. These results were consistent with findings by Busseri (2018), namely that a country's economic development may be one of the factors that explains variability in the correlation between the affective and cognitive components of SWB in samples of different ages. In a similar vein, results obtained for an adult population by Kikutani et al. (2016) showed emotional structure to be influenced by the socioeconomic situation in each country. In respect of this, further results published by Casas et al. (2020) suggested that the socioeconomic factor should be considered in cross-cultural comparisons of SWB involving children. In addition, future research should also investigate how these factors can influence the value attributed to PA, which constitute a key aspect in understanding the relationship between PA and more global appraisals of SWB (Tamir et al. 2016).

GDP per capita is not the only economic indicator frequently used at the national level. It is also calculated differently by different organizations (e.g. the International Monetary Fund -IMF-, the United Nations -UN-, the World Bank, among others), yielding varying results. In fact, the IMF even has two ways of calculating this value: PPP (Purchasing Power Parity) and nominal. It is therefore unclear to what extent the failure to identify a relationship between economic and children's SWB indicators at the national level may be due to the concrete indicators chosen, given that the four 
previously quoted studies employed different SWB indicators and only one or two economic indicators each.

According to Newland et al. (2019), "GDP was weakly predictive of life satisfaction, and the Gini coefficient was not a significant predictor of life satisfaction" (page 409), even if they also state that "GDP, an indicator of a country's income and economic growth, has been related to other indices of well-being, including health and happiness" (page 399), it can be seen as only a limited indicator of economic well-being, and additional indices, such as the Gini coefficient, have been recommended as a supplementary indicator to capture country-level economic health more holistically (Conceição \& Bandura, 2008; Ovaska \& Takashima, 2006; Schyns, 1998, 2002).

In summary, all of the above being said, despite country-level indicators, including GDP and the Gini coefficient, having been examined in a handful of studies predicting children's SWB (Klocke, Clair, \& Bradshaw, 2014; Lee \& Yoo, 2015; Levin et al., 2011), findings have been inconclusive. The relationship of affective components of SWB with economic indicators at national level have been rarely explored, and still more scarcely using children's SWB indicators. More work therefore needs to be done to tease apart potential macro- and microsystem influences on children's SWB.

Most prior research on the topic has analysed the relationship between the aforementioned objective and subjective indicators in children's populations without carrying out a separate analysis by age group. There is cumulative evidence that children's SWB decreases with age from 10 to 16 (Casas \& González-Carrasco, 2020), and it is possible that the association between objective and subjective indicators will be observed for some age groups but not for others. It may even happen that economic indicators increase their association with children's age, provided previous research found no association with children's SWB but identified association with adults, at national level.

Important gaps can still be found in those studies that have explored variations in children's SWB at the country level to date. Firstly, only few studies have examined the impact of economic indicators on cognitive and affective components of SWB at these ages, and even fewer have explored the relationship between these components among countries. Secondly, considering that childhood is a developmental stage comprising constant physical, cognitive and emotional changes, it is not clear how these economic indicators may influence the different components of SWB in different children's age groups.

The present study therefore makes two new contributions: on the one hand, it includes four economic indicators to provide a more comprehensive knowledge of economic wealth and wealth inequality at the country level, and four overall SWB indicators (plus two indicators relating cognitive and affective measures), and on the other, it explores the relationships between the economic indicators and more specific SWB items. This is done by separating 10 and 12-year-olds into different age groups for each data analysis in order to offer a more detailed overall panorama of the relationship between children's subjective and objective indicators at the macrosocial level.

Since Andrews and Withey (1976) found that life satisfaction formed a separate factor from the two major types of affect, many authors have made further contribu- 
tions to develop the "Tripartite Theory" of SWB (Arthaud-Day et al., 2005; Busseri, 2018; Metler \& Busseri, 2017). At the end of the last century, Diener et al. (1999, page 277) already recommended that "the major components of SWB should be assessed separately in future research" (page 277). In the present study we will therefore not only use cognitive measures of SWB like most previous research, but also affective measures, and the quadripartite perspective of SWB, including overall satisfaction with life and life domains, positive affect and negative affect (Savahl, Casas, \& Adams, 2021) will be considered.

\section{The present study}

The aims of this study are twofold:

1. To explore whether associations are observed between any of the economic indicators and SWB indicators used here at the national level for age groups 10 and 12 .

2. To explore which economic indicators have predictive capacity for any of the SWB indicators used here at the national level for age-groups 10 and 12.

\section{Method}

\subsection{Participants}

The data-set was obtained from 10 and 12-year-old groups of the $\mathrm{ChW}$ international survey (third wave) by means of group-administered questionnaires in the school context within each country. An international committee of the Children's Worlds survey supervised the design of data collection in each country to guarantee the appropriate representativeness of the data for each region or country. More details on the data collection procedure in each country can be obtained from the project's website (www.isciweb.org) and from the third wave report by Rees et al. (2020).

The sample was composed of $\mathrm{N}=48,499$ 10-year-olds from 35 countries, and $\mathrm{N}=44,692$ 12-year-olds from 30 countries.

\subsection{Instruments}

Four economic indicators were used in this study, three pertaining to wealth and one to wealth inequality. These were: the Gross Domestic Product (GDP) Purchasing Power Parity per capita (GDP PPP) estimations made by the International Monetary Fund (IMF) for 2021; the GDP nominal per capita estimated by the IMF for 2021; the Wealth per Adult (WpA) mean in United States dollars calculated by Credit Suisse for 2019; and the Gini coefficient calculated by the World Bank for 2018, respectively. GDP estimates by the IMF were chosen because the same estimations by the United Nations or the World Bank do not include Taiwan, which was included in the third wave of the Children's Worlds international dataset. 
Four overall SWB indicators were used. The first one was the five-item version of the Children's Worlds Subjective Well-Being (CW-SWBS5) multi-item contextfree cognitive psychometric scale, which Casas and González-Carrasco (2021) validated and tested for cross-country comparison for the same countries included in the present study; items were: 'My life is just as it should be', 'The things in my life are excellent', 'I like my life', 'I enjoy my life', and 'I'm happy with my life'-its scores presented in an 11-point scale, from Do not agree at all to Totally agree. The second and third ones were the Positive Affect (PA) and Negative Affect (NA) scales included on the Children's Worlds Positive and Negative Affect Scale (CW-PNAS) (Casas \& González-Carrasco, 2021) - the wording of these was To what extent have you felt like this in the last two weeks? and answers were provided on a 0-10 scale from Not at all to Extremely (PA included 'happy', 'calm', and 'full of energy', and NA 'sad', 'stressed', and 'bored'). The fourth one was the single-item cognitive scale on overall life satisfaction (OLS), as used in the third wave of the Children's Worlds project-scores being presented on a $0-10$ scale from Not satisfied at all to Completely satisfied. Correlations were calculated between the PA and the OLS (PA↔OLS), and between the NA and the OLS (NA↔OLS), and the findings were used as additional SWB indicators.

Twelve items on satisfaction with specific life domains were also used as SWB indicators, as detailed in Table 2. These were also taken from the third wave of the Children's Worlds project. Answers were on 0-10 scales, ranging from Not satisfied at all to Completely satisfied.

\subsection{Procedure}

The data-set used for this analysis was cleaned and prepared within the international project prior to the database being made available. This process included identifying and excluding cases with high proportions of missing data and identifying and excluding cases with systematic response patterns. The latter point is of relevance to this article given that some authors, such as Cummins and Lau (2005), recommend excluding from the analysis respondents who score at the top or bottom of the scale for all items on the PWI-SC, because constant extreme answers tend not to be reliable. There are problems with this approach, however, in that it automatically excludes anyone who expresses complete satisfaction with all aspects of their life covered by one instrument - and many children at these ages seem to be extremely satisfied with many aspects of their lives, even if that does not mean they are satisfied with all aspects measured by other instruments. According to Rees and Main (2015), it is possible to adopt a broader approach when using Children's Worlds data sets because the questionnaire includes different sets of items. Therefore, uniform response patterns were identified for five different sets of items in the data set and cases were excluded if they exhibited such patterns for more than one of these sets (Rees \& Main, 2015).

The sample used in this paper was subjected to a second cleaning. Children who did no answer three or more items on any of the psychometric scales were excluded from the analysis, while the scores of those not answering one or two items were 
substituted by means of multiple imputation using regression, as implemented via the AMOS25 software.

\subsection{Data Analysis}

Separate correlations were calculated between all economic and SWB indicators for each age group, and also between all economic indicators and the selected satisfaction items. Next, systematic linear regressions were calculated for each economic indicator on each SWB general indicator, and also for each economic indicator on the selected satisfaction items. Because this is a preliminary exploratory analysis, examining interaction effects among variables was not the aim. Regressions were carried out separately for the 10 and 12-year-old groups using the SPSS27 software.

\section{Results}

\subsection{Correlations}

Correlations between the four economic indicators and six children's SWB indicators at the national level are presented in Table 1, with the aggregated data base being used separately for each age group. As expected, the three wealth indicators displayed very high and significant correlations with one another, in contrast with the Gini coefficient, which displayed a moderate negative correlation with all three for both age groups - not reaching significance with WpA.

The GDP (PPP), the GDP (nominal) and the WpA displayed significant negative correlations with the PA for the two age groups, whereas the strongest correlation between one these and a general indicator of SWB was with the NA $\leftrightarrow$ OLS (correlation between Negative Affect and the OLS) for the two age groups. No other correlation of these three wealth indicators reached significance.

The Gini coefficient displayed a significant positive correlation with NA for both age groups, and with NA↔OLS only for the 10-year-old group.

Table 2 presents correlations between the four economic indicators and twelve children's satisfaction domains at the national level, with the aggregated data base being used separately for each age group.

The GDP (PPP), the GDP (nominal) and the WpA displayed significant negative correlations with satisfaction with life as a student for both age groups. Additionally, the GDP (PPP) displayed a significant moderate positive correlation with 'satisfaction with friends' and with 'satisfaction with the things you have' for the 10-yearolds, and a significant negative correlation with 'satisfaction with the way you look' for the 12-year-olds. GDP (nominal) also displayed a significant moderate positive correlation with 'satisfaction with the things you have' for the 10 year-olds and with 'satisfaction with friends' for both 10 and 12-year-olds. The WpA also displayed a significant moderate negative correlation with 'satisfaction with how you use your time' and with 'satisfaction with the way you look' only for the 12-year-olds.

The Gini coefficient displayed significant negative correlations with satisfaction with the people you live with, satisfaction with friends, satisfaction with the area 


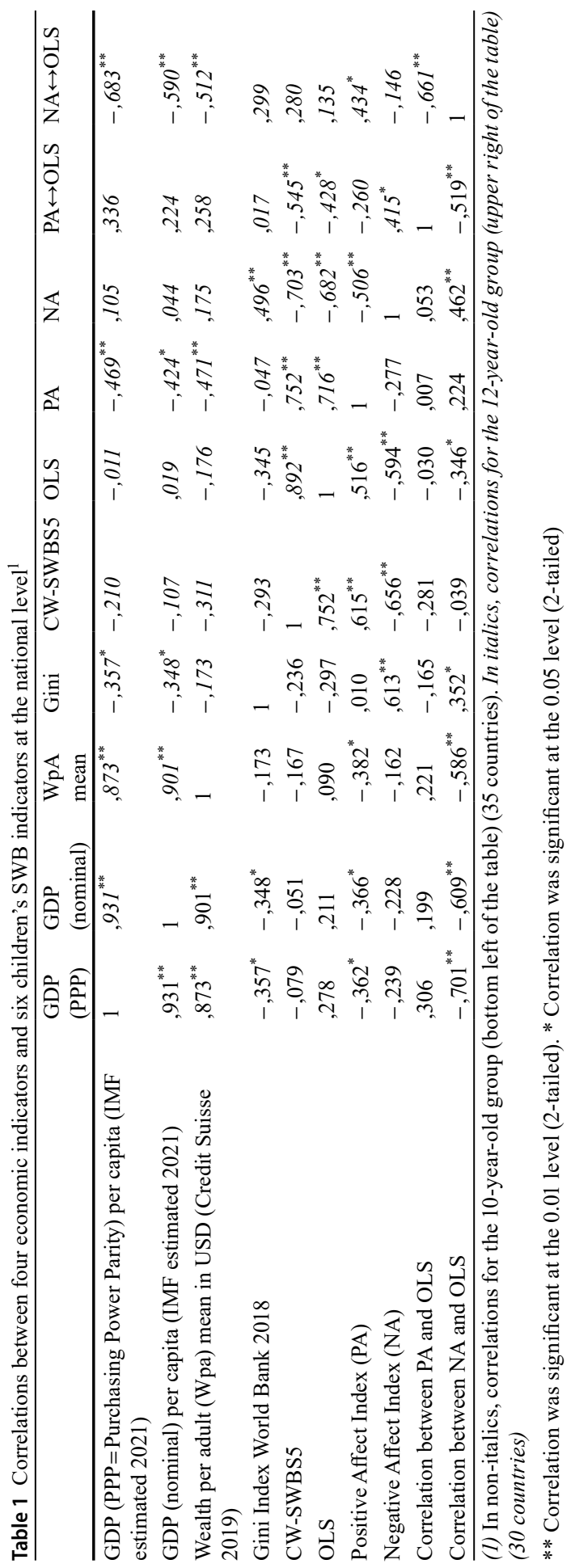


you live in, and satisfaction how you are listened to by adults for both age groups, although most of these were stronger for the 12-year-olds. Additionally, it also displayed significant negative moderate to high correlations with satisfaction with what may happen later in your life for the 10-year-olds and satisfaction with the things you have, with how you use your time, with how safe you feel and with the freedom you have for the 12-year-olds.

\subsection{Regressions}

Table 3 presents systematic linear regressions for each economic indicator on each of the SWB indicators used here. No regression was found to be significant when carried out on any of the overall cognitive SWB instruments (the CW-SWBS5 and the OLS), or on the PA $\leftrightarrow$ OLS. However, results differed when using affective SWB instruments or satisfaction with some specific life domains.

The three indicators of economic wealth displayed significant contributions to PA and to the NA $\leftrightarrow$ OLS for both age groups (Table 3; see Figs. 1, 2, 3 and 4 as examples of the regression plots, and the supplementary materials), while the inequality indicator (Gini index) displayed a significant contribution to NA for both age groups and to the NA $\leftrightarrow$ OLS for the 10-year-olds (Table 3; see Figs. 5 and 6 as examples, and the supplementary materials).

When the dependent variable was one of the satisfaction items, the results were as follows: the three indicators of wealth displayed a significant contribution to satisfaction with life as a student (two age groups) (Table 3; see Figs. 7 and 8 as examples, and the supplementary materials). Regression on any other satisfaction item did not show any other coincidence of the three wealth indicators. The GDP (PPP) displayed a significant contribution to satisfaction with the things you have (10-year-olds), satisfaction with the way you look (12-year-olds), satisfaction with how safe you feel (10-year-olds), satisfaction with your friends (10-year-olds), and satisfaction with the freedom you have (10-year-olds). GDP (nominal) made a significant contribution to satisfaction with the things you have (10-year-olds), satisfaction with your friends (both age groups) and satisfaction with the freedom you have (10-year-olds). The WpA mean made a significant contribution to satisfaction with the way you look (12-year-olds) and satisfaction with how you use your time (12-year-olds) (see Table 3 and supplementary materials).

The Gini index made a significant contribution to satisfaction with the things you have (12-year-olds), satisfaction with how safe you feel (12-year-olds), satisfaction with friends (both age groups), satisfaction with how you use your time (both age groups) and satisfaction with the freedom you have (both age groups) (see Table 3 and supplementary materials).

\section{Discussion}

In this research, we have explored the correlations between economic and children's SWB indicators at the country (national) level, and the regressions of the economic indicators on different SWB-related indicators. The inclusion of four economic indi- 


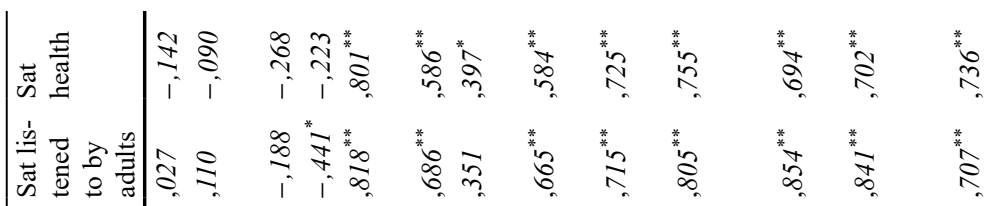

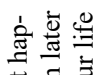

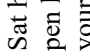

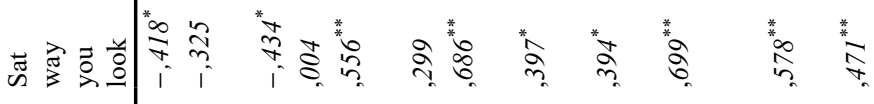

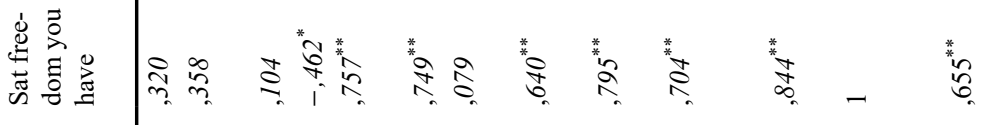

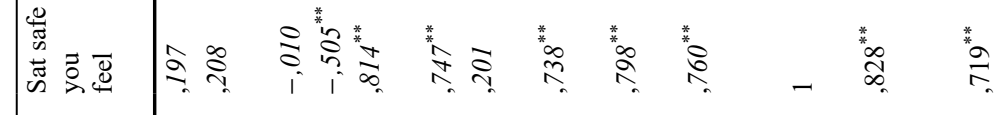

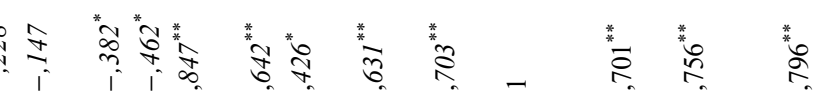

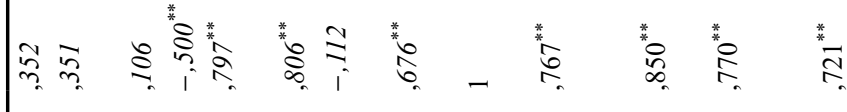

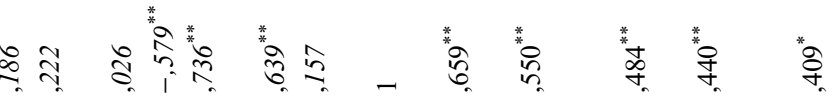

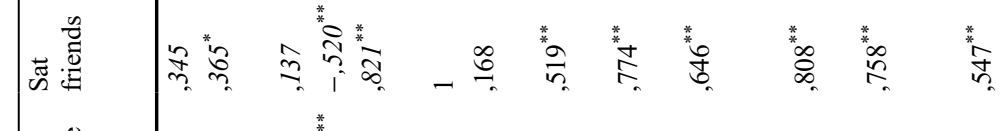

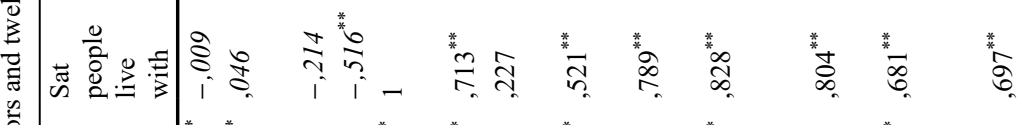

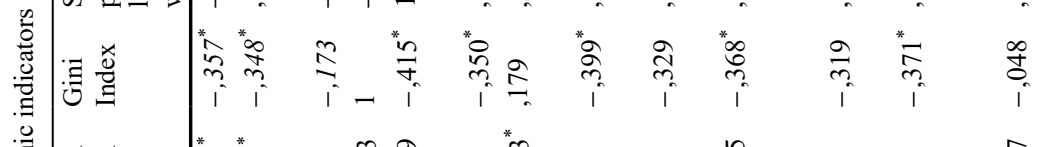

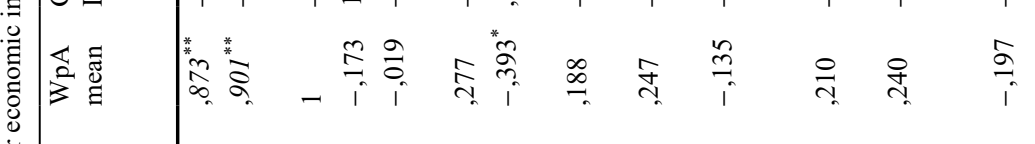

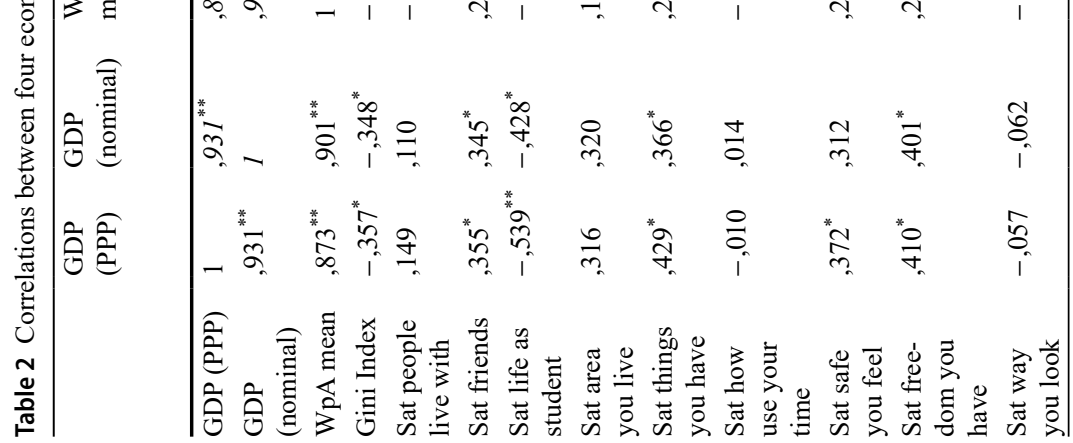




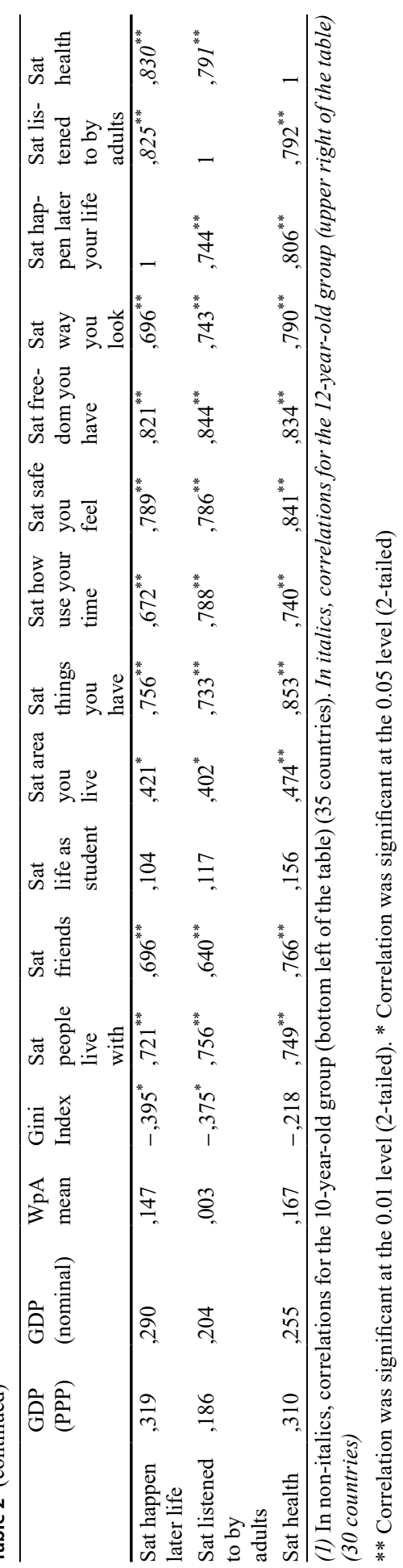


cators was found to be very useful, as their relationship with each SWB indicator differed in several cases, even if three of them were apparently very similar and displayed a high correlation with one another.

The results obtained suggest that the wealthier the country (according to the three economic indicators), the lower the children's scores for Positive Affect and the lower the correlation between Negative Affect and the OLS for children this being the case for both the 10 and the 12-year-old age groups. Formulated the other way around, we can say that the poorer a country is in economic terms, the more consistency there is between NA and the cognitive SWB of their children. Children in wealthy countries tend to report high cognitive SWB more frequently, despite their NA also being high.

At the same time, the higher the wealth inequality within a country, the higher its children's scores with regard to NA also for both age groups. Furthermore, the higher the inequality of a country, the higher the correlation between NA and the OLS of its children, although this correlation only reaches significance for the 10 -year-old group.

Unlike with the second wave data set (which analysed 18 countries) (Casas et al., 2020), when using the third wave, economic indicators did not significantly correlate with the PA $\leftrightarrow$ OLS, although they did with NA $\leftrightarrow$ OLS and with PA. The correlation between economic indicators and the OLS was non-significant for both the second and third waves, however.

These results reveal that the affective and cognitive components of children's SWB display idiosyncratic associations with both wealth and inequality indicators at the national level, and that it is very important to analyse them separately. Previous research has mainly analysed the relationship between national income and income inequality indicators with measures of the cognitive component of SWB, observing very moderate or null associations (Levin et al., 2011; Main et al., 2019). The results of the present study show notable significant associations between said indicators and different affective components of SWB at the country level. Furthermore, the results also confirm that the correlation between affective measures and cognitive measures of SWB is influenced by the wealth and inequality of a country, supporting the hypothesis formulated by Busseri (2018) that economic development may explain the variability in said correlation in samples of different ages, and extending to children the hypothesis that the emotional structure of people in any given country or culture is influenced by its socioeconomic situation (Kikutani et al., 2016).

This research has also contributed a new way of exploring which of the above economic indicators have predictive capacity for any of the specific items on satisfaction with different domains or aspects of children's lives at the national level, for both of the age groups investigated here. First, we explored children's satisfaction with people they live with. This satisfaction item displayed a significant association with the Gini coefficient for both age groups, suggesting that in-country wealth inequalities may have a negative impact on everyday relationships within the household. However, no significant association was observed with the other three wealth indicators. The same results were observed for children's satisfaction with how adults listen to them, which displaying a significant association with the Gini coefficient and a non-significant one with the other wealth indicators, suggesting that adults tend to listen to their children more in wealthier countries. Similar results were obtained for 


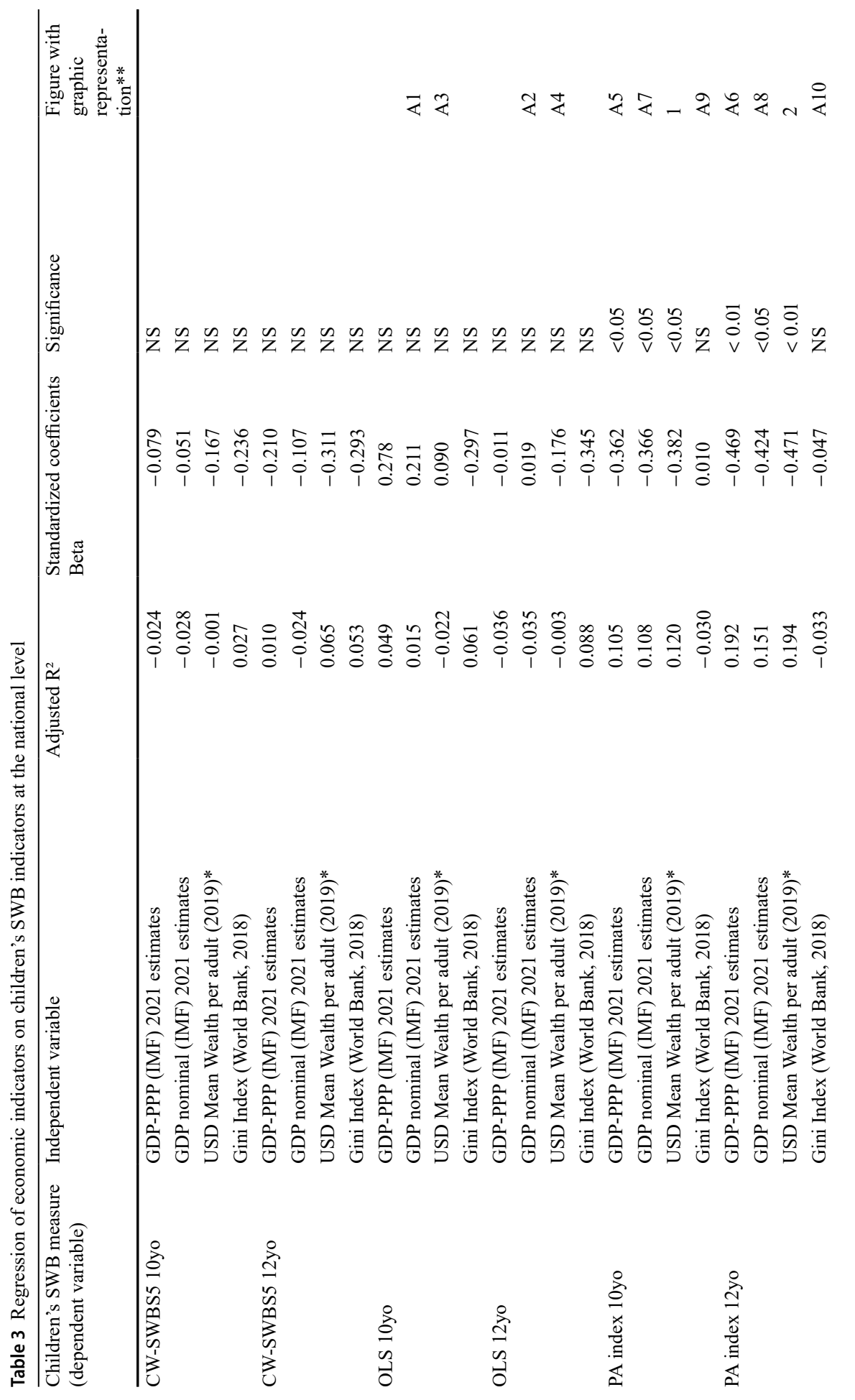




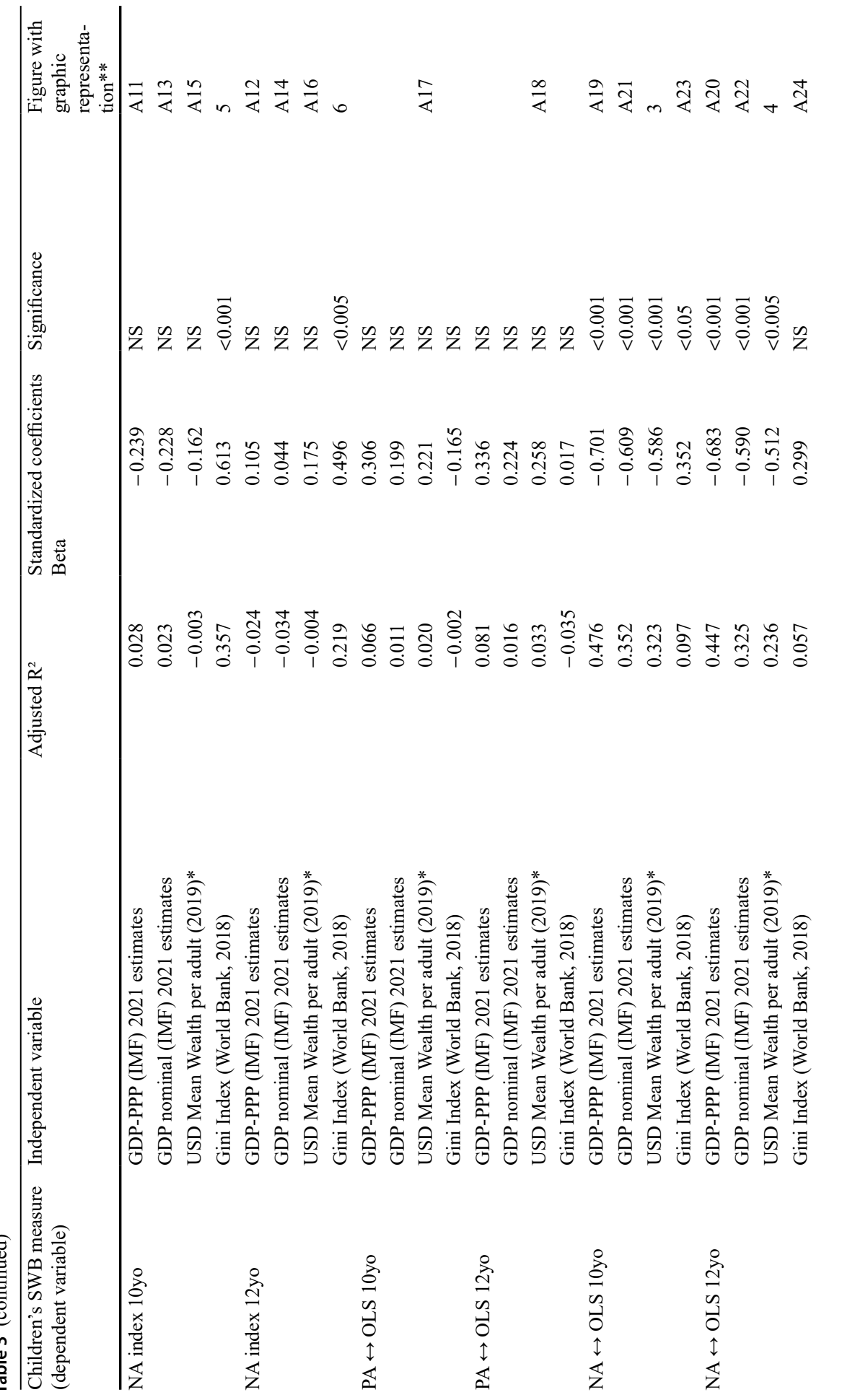




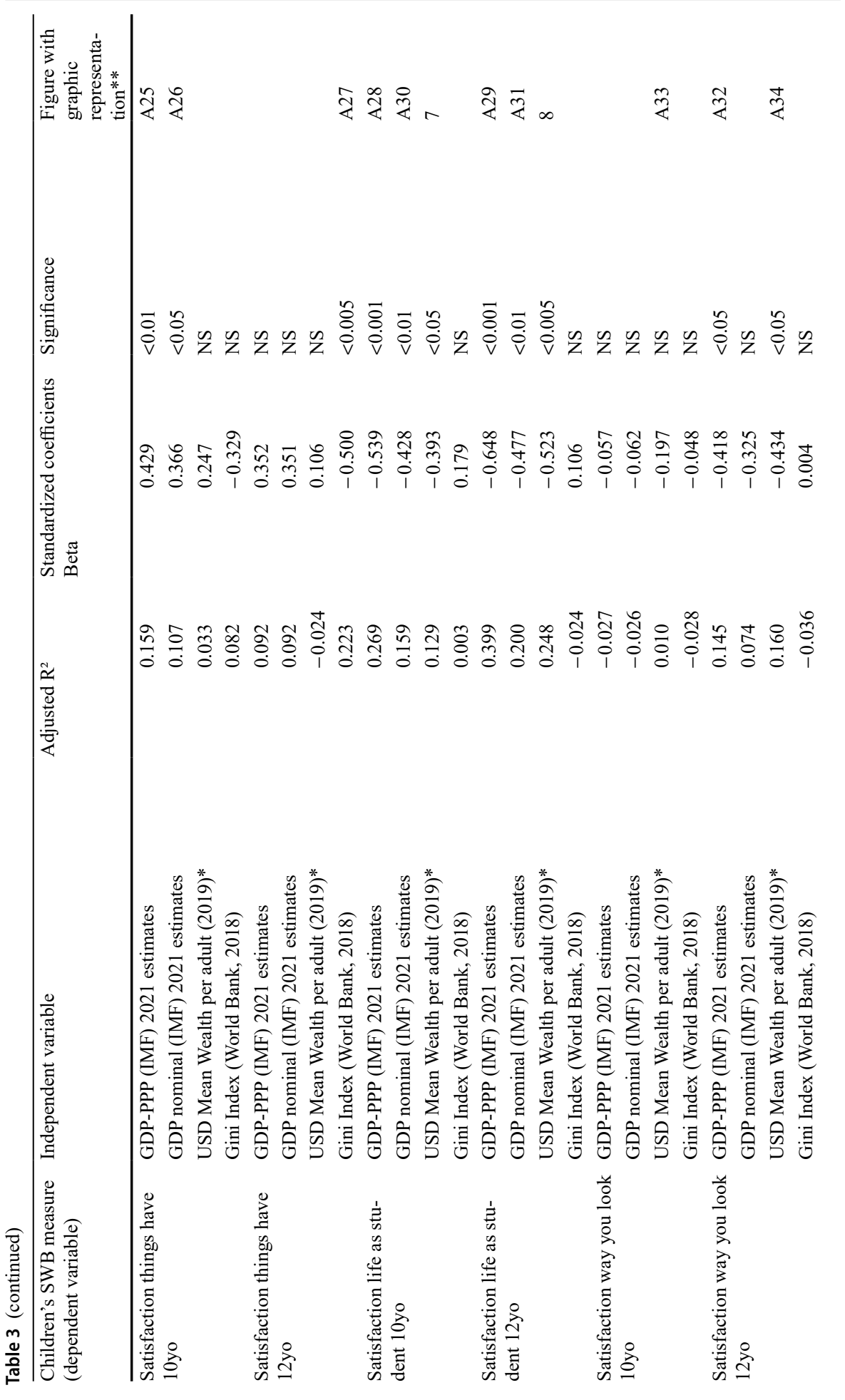




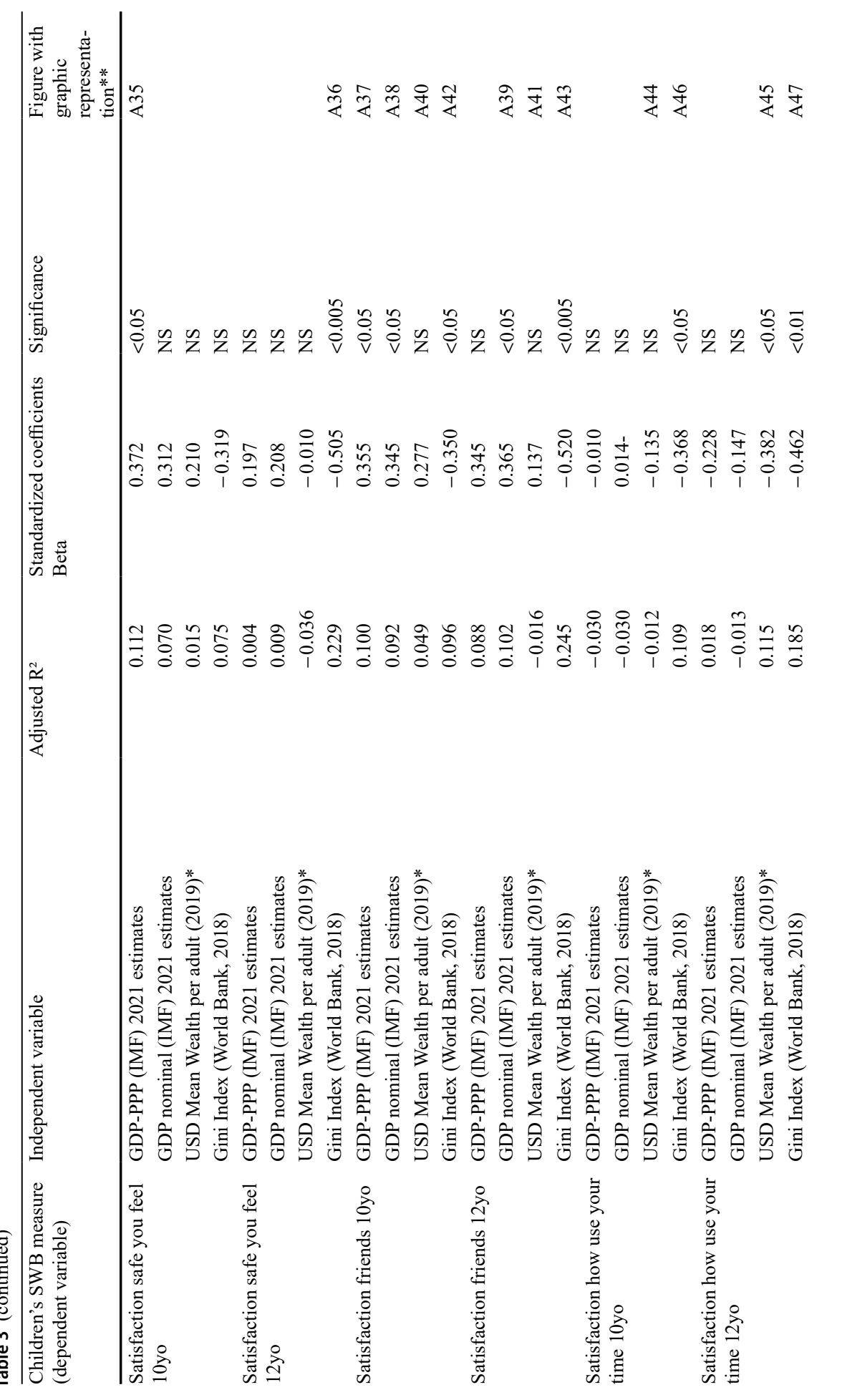




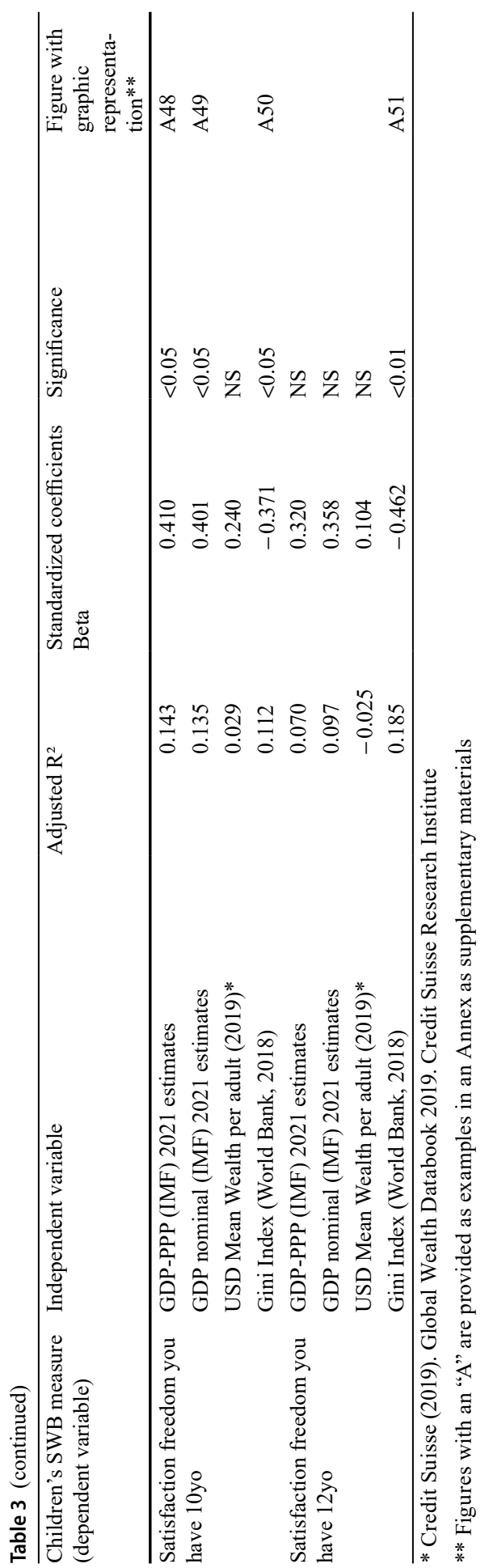


Fig. 1 Regression of WpA on 10 year-old children's Positive Affect

Fig. 2 Regression of $\mathrm{WpA}$ on 12 year-old children's Positive Affect

Fig. 3 Regression of WpA on 10 year-old children's correlation between Negative Affect and the OLS
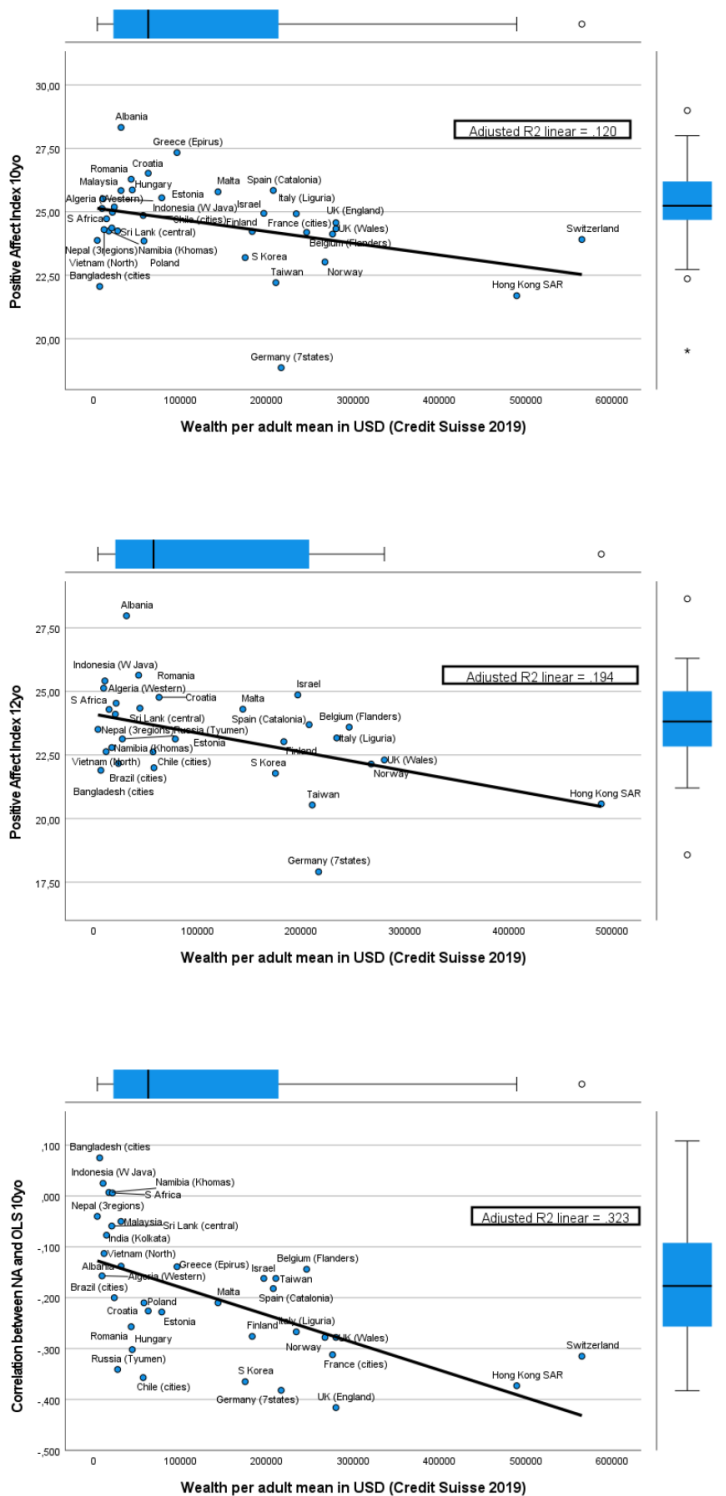

satisfaction with the area you live in, suggesting the larger the wealth inequalities in a country, the more children are dissatisfied with their neighbourhood, probably due to areas intended for children's leisure time activities being more poorly equipped. These results seem to be consistent with research on neighbourhood satisfaction among adolescents from different socio-economic contexts within the same country (Aminzadeh et al., 2013; Oyarzún et al., 2019; Wang \& Fouler, 2019).

Children's satisfaction with their health did not display any significant association with any of the four economic indicators used here, suggesting that satisfaction with 
Fig. 4 Regression of WpA on 12 year-old children's correlation between Negative Affect and the OLS

Fig. 5 Regression of Gini Index on 10 year-old children's Negative Affect

Fig. 6 Regression of Gini Index on 12 year-old children's Negative Affect
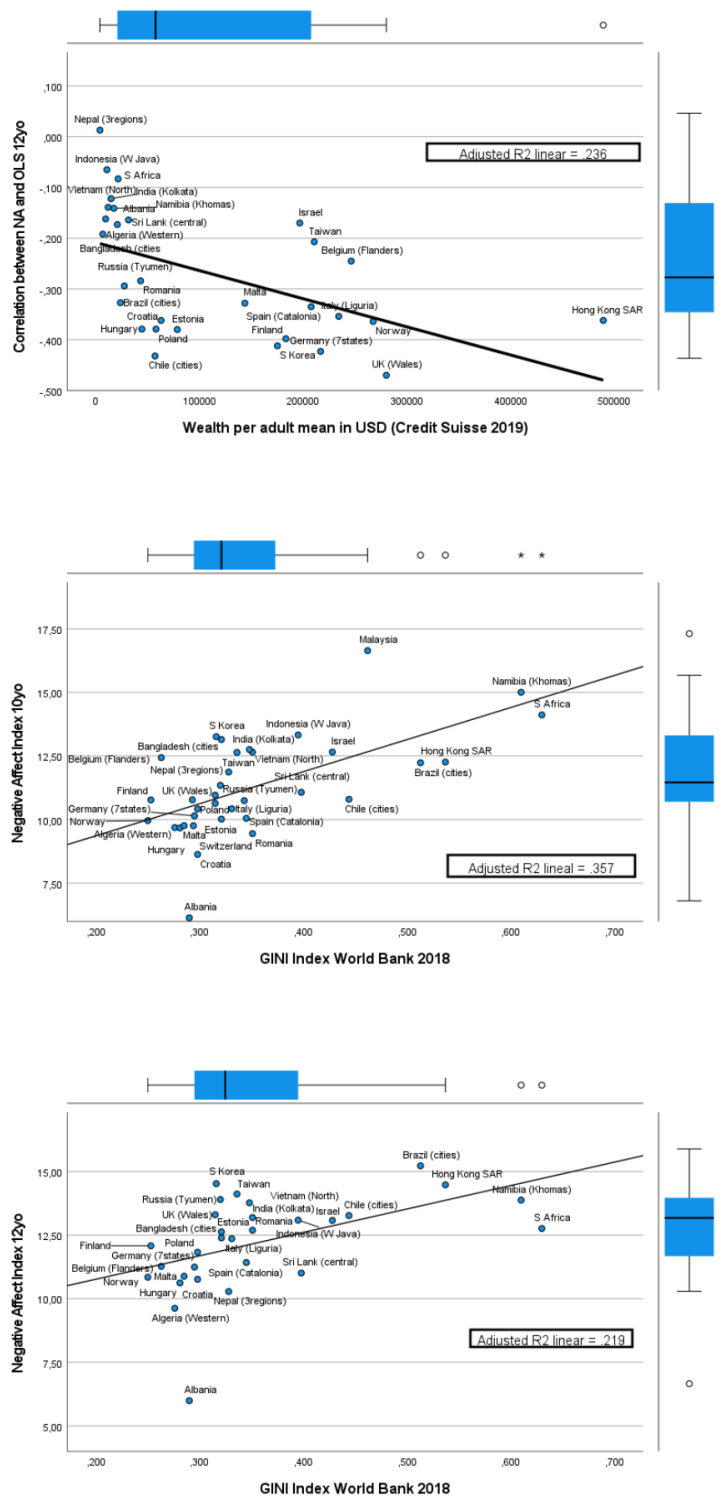

health is a very personal issue that depends more on individual circumstances than on indicators at the national level.

Our results suggest that the wealthier a country is, the lower their children's satisfaction with their life as students. Wealthier countries appear to have more demanding, competitive and stressful school systems, which has negative consequences for children's well-being at the ages of both 10 and 12 (e.g. Figures 7 and 8). Previous research has suggested this is particularly important among boys (Rees et al., 2020).

In contrast, the larger the wealth inequality within a country, the lower the satisfaction with friends in both age groups, suggesting competitiveness for wealth may 
Fig. 7 Regression of WpA on 10 year-old children's satisfaction with life as a student

Fig. 8 Regression of WpA on 12 year-old children's Satisfaction with life as a student
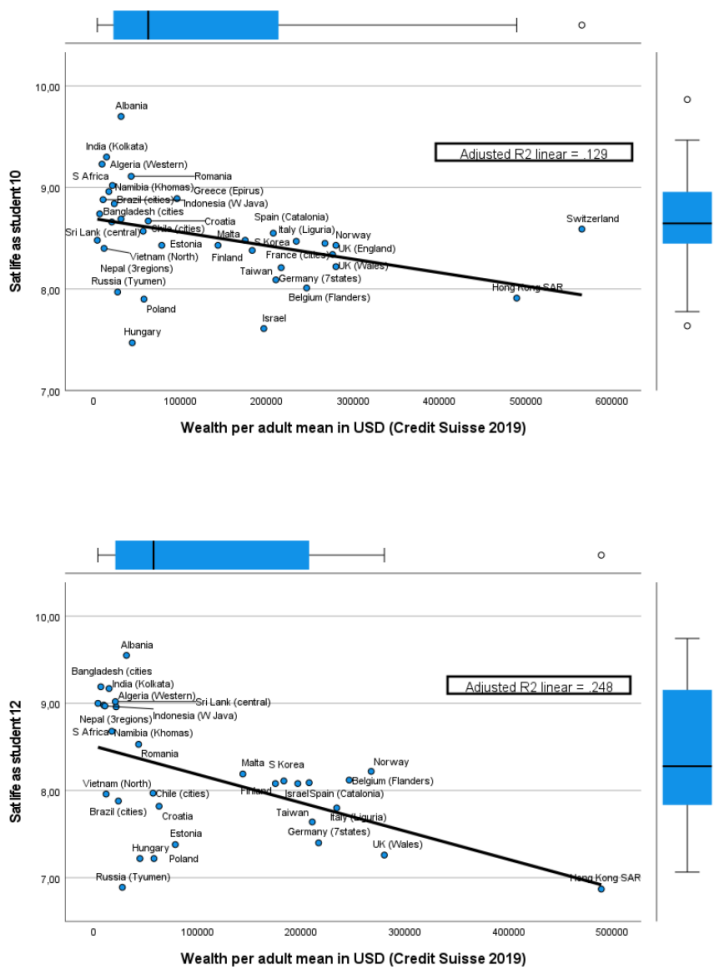

negatively influence being happy with friends and doing more high-quality activities with friends. However, at least one economic indicator for each age group displayed a positive association with satisfaction with friends, suggesting a wealthy context may also facilitate high-quality activities with friends. Given these complex results, satisfaction with friends appears to be a promising field for future research on children's well-being at the national level.

A trend is observed that the wealthier the country, the lower the satisfaction with self-image reported by 12 -year-olds. Interestingly, this association is only significant when using the GDP-PPP and the WpA, but not when using the GDP nominal indicator, suggesting that not all economic indicators have the same relationship with SWB variables at the national level (e.g. Figure A1, in supplementary materials). Prior research has pointed out that a lower satisfaction with self-image may be particularly important among girls in wealthier countries, due to the cultural pressure to have a perfect body according to standards presented in the media (Rees et al., 2020).

At this same age, the wealthier the country according to the $\mathrm{WpA}$, the lower children's satisfaction with their use of time. However, this negative correlation is not observed with the other two economic indicators used here, suggesting a difference in sensitivity in this regard (e.g. Figure A2). Children's satisfaction with their use of time also displays a significant negative association with the Gini coefficient for the two age groups, suggesting the larger the wealth inequalities in a country, the lower children's satisfaction with this life domain. This may be attributed to the fact that 
children in less wealthy countries often have a less structured daily agenda, which in turn may be associated with a feeling of wasting time.

The item on satisfaction with the freedom children perceive is also negatively and significantly associated with the Gini coefficient for the two age groups and positively associated with two of the three wealth indicators at the age of 10 -none of the three reaching significance for the 12-year-old age group. These results suggest wealth inequalities within a country may have a negative impact on the feeling of freedom children experience.

A notable negative association is observed between the Gini coefficient and satisfaction with the things children have at the age of 12 - this not reaching significance among the 10-year-olds. However, a significant positive association is observed between two wealth indicators (GDP-PPP and GDP nominal) and this satisfaction domain at the age of 10 - which did not reach signification for any wealth indicator at the age of 12 .

At the age of 10, children's satisfaction with what may happen to them later in life displays a significant negative association with the Gini coefficient. This relationship does not reach significance in the 12-year-old group. No association is observed with the three wealth indicators.

At this same age (the 10-year-old group), the wealthier the country, the higher the satisfaction with safety-although this positive correlation is only significant with the GDP-PPP and not with the other two wealth indicators, once again suggesting that each economic indicator may differ in terms of sensitivity depending on the domain. However, at the age of 12 , there is a highly significant association between this domain and the Gini coefficient, while associations with any other wealth indicator do not reach significance. These results suggest that feelings of safety may change between 10 and 12 years of age, perhaps due to the child's greater autonomy and better knowledge of the surrounding world, while children's greater perception of wealth inequalities in their country have a negative impact on their feeling of safety. Thus, these results also contribute evidence that different economic indicators may have very different relationships with children's SWB indicators, despite all wealth indicators displaying a high correlation with one another.

Despite some differences have been identified in this study between in the correlation of different economic and SWB indicators at the age of 10 and of 12, data do not allow to anticipate the evolution of these correlations at older ages. While cognitive SWB indicators at these ages do not correlate with economic indicators, but cumulative evidence is available showing they do with adults, at national level, an important question raises: at what age or ages SWB indicators start to correlate with economic indicators at national level?

\section{Conclusions}

The associations between widely used economic measures (including both wealth and wealth inequality indicators) and affective components of children's SWB revealed in this research contribute to questioning the hitherto widespread belief that a country's macro-economic situation has little or no impact on children's well-being. This 
finding invites the use of such indicators to monitor the implementation of public policies aimed at children, as already done with other indicators by several authors (e.g.: Bradshaw \& Richardson, 2009; Casas et al., 2013b).

Notable relationships have also emerged in this study between economic indicators and cognitive and affective components of children's SWB, leading to an interest in considering children's SWB from a quadripartite conception-including overall satisfaction with life and life domains, positive affect and negative affect (Savahl, Casas, \& Adams, 2021) — as far as economic indicators are concerned. It is precisely this understanding of the structure of children's SWB that has led to the observation that satisfaction with some specific life domains may display associations with several economic indicators at the macro level, while satisfaction with other life domains may not-meaning that overall life satisfaction may offer different results depending on children's satisfaction with a set of different life domains in each country. The comparison by age group has also revealed that these associations may change with age in some cases.

\section{Limitations and Future Directions}

All of the data used in this study were cross-sectional and no causal relationships can therefore be established between variables. Future research will require longitudinal data in order to better understand the associations between the objective and subjective indicators used here.

Future research should also investigate whether relationships between economic indicators and SWB indicators display gender differences at the national level, given that previous research has found cross-cultural gender differences in some satisfaction domains, such as satisfaction with school and with the way children look. Subjective economic indicators might also be explored. An analysis that considers family affluence as a mediating factor between both cognitive and affective indicators of SWB and economic variables, like the ones analysed here, would be an interesting future direction for research, as would the use of regression analysis to identify potential interaction effects among the variables considered in this article and new ones.

Although the dataset used here included representative samples from 35 countries for the 10-year-olds and 30 for the 12-year-olds, respectively, the results cannot be generalized world-wide. Data from more countries and cultures should be collected in the future to better understand cross-cultural diversity in the phenomena studied here. Also, data from a broader range of age-groups is needed, particularly from older adolescents, allowing to identify at what ages SWB indicators start to correlate with economic indicators at national level. Future research might also incorporate children's well-being indicators from an eudaimonic perspective, which were not considered in the present study.

Supplementary Information The online version contains supplementary material available at https://doi. org/10.1007/s12187-022-09918-4. 
Acknowledgements Thanks are due to all children who kindly agreed to answer the questionnaire, to all principal investigators and to all research team members who participated in the data collection in the 35 countries included in the sample used here and to the co-ordinating team of the Children's Worlds project for kindly allowing us to use the database, to the Jacobs Foundation for supporting the project, and to Barney Griffiths for the English editing of this paper.

Funding Open Access funding provided thanks to the CRUE-CSIC agreement with Springer Nature.

Conflict of Interest On behalf of all authors, the corresponding author states that there is no conflict of interest. Legal and ethical standards corresponding to each country have been strictly adopted for the data collection. Informed consent has been collected from both parents and children.

Open Access This article is licensed under a Creative Commons Attribution 4.0 International License, which permits use, sharing, adaptation, distribution and reproduction in any medium or format, as long as you give appropriate credit to the original author(s) and the source, provide a link to the Creative Commons licence, and indicate if changes were made. The images or other third party material in this article are included in the article's Creative Commons licence, unless indicated otherwise in a credit line to the material. If material is not included in the article's Creative Commons licence and your intended use is not permitted by statutory regulation or exceeds the permitted use, you will need to obtain permission directly from the copyright holder. To view a copy of this licence, visit http://creativecommons.org/ licenses/by/4.0/.

\section{References}

Aminzadeh, K., Denny, S., Utter, J., Milfont, T. L., Ameratunga, S., Teevale, T., \& Clark, T. (2013). Neighbourhood social capital and adolescent self-reported wellbeing in New Zealand: A multilevel analysis. Social Science \& Medicine, 84, 13-21. https://doi.org/10.1016/j.socscimed.2013.02.012

Andrews, F. M., \& Withey, S. B. (1976). Social indicators of well-being: American's perceptions of life quality. Plenum Press

Arthaud-Day, M. L., Rode, J. C., Mooney, C. H., \& Near, J. P. (2005). The subjective well-being construct: A test of its convergent, discriminant, and factorial validity. Social Indicators Research, 74(3), 445-476. https://doi.org/10.1007/s11205-004-8209-6

Bradshaw, J., \& Richardson, D. (2009). An index of child well-being in Europe. Child Indicators Research, 2, 319-351. https://doi.org/10.1007/s12187-009-9037-7

Bradshaw, J., \& Rees, G. (2017). Exploring national variations in child subjective well-being. Children and Youth Services Review, 80, 3-14. https://doi.org/10.1016/j.childyouth.2017.06.059

Busseri, M. A. (2018). Examining the structure of subjective well-being through meta-analysis of the associations among positive affect, negative affect, and life satisfaction. Personality and Individual Differences, 122, 68-71. https://doi.org/10.1016/j.paid2017.10003

Casas, F., Bello, A., González. M., \& Aligué, M. (2013). Children’s subjective well-being measured using a composite index: What impacts Spanish first-year secondary education student's subjective wellbeing? Child Indicators Research, 6, 433-460. https://doi.org/10.1007/s 12187-013-9182-x

Casas, F., Bello, A., González, M., \& Aligué, M. (2013b). Children's subjective well-being measured using a composite index: What impacts Spanish first-year secondary education students' subjective wellbeing. Child Indicators Research, 6(3), 433-460

Casas, F., Oriol, X., \& González-Carrasco, M. (2020). Positive Affect and its Relationship with General Life Satisfaction among 10 and 12-Year-Old Children in 18 Countries. Child Indicators Research, 13, 2261-2290. https://doi.org/10.1007/s12187-020-09733-9

Casas, F., \& González-Carrasco, M. (2021). Analysing comparability of four multi-item well-being psychometric scales among 35 countries using Children's Worlds 3rd wave 10 and 12-year-olds samples. Child Indicators Research, 14, 1829-1861. https://doi.org/10.1007/s12187-021-09825-0

Conceição, P., \& Bandura, R. (2008). Measuring subjective wellbeing: A summary review of the literature. Retrieved from http://web.undp.org/developmentstudies/docs/subjective_wellbeing_conceicao_bandura.pdf 
Cummins, R. A., \& Lau, A. L. D. (2005). Personal well-being index-school children (PWI-SC). Manual. 3rd ed. Melbourne: School of Psychology, Deakin University. Available online at http://www.deakin. edu.au/research/acqol/instruments/wellbeing-index/pwi-school.pdf

Diener, E., \& Oishi, S. (2000). Money and happiness: Income and subjective well-being across nations. In E. Diener \& E. M. Suh (Eds.), Culture and subjective well-being (pp. 185-218). The MIT Press

Diener, E., Suh, E. M., Lucas, R. E., \& Smith, H. L. (1999). Subjective well-being: Three decades of progress. Psychological Bulletin, 125(2), 276-302

Gross-Manos, D. (2017). Material well-being and social exclusion association with children's subjective well-being: Cross-national analysis of 14 countries. Child and Youth Services Review, 80, 116-128. https://doi.org/10.1016/j.childyouth.2017.06.048

Helliwell, J. F., Layard, R., \& Sachs, J. (Eds.). (2015). World happiness report 2015. http://www.theglobeandmail.com/news/national/article24073928.ece/BINARY/World+Happiness+Report.pdf

Kikutani, M., Ikemoto, M., Russell, J., \& Roberson, D. (2016). Cultural influences on the structure of emotion: An investigation of emotional situations described by individuals from Cambodia, Japan, UK and US. International Journal of Applied Psychology, 6(1), 20-26. https://doi.org/10.5923/j. ijap. 20160601.04

Klocke, A., Clair, A., \& Bradshaw, J. (2014). International Variation in Child Subjective Well-Being. Child Indicators Research, 7, 1-20. https://doi.org/10.1007/s12187-013-9213-7

Land, K. C., Lamb, V. L., \& Fu, Q. (2015). Measuring trends in child well-being and child suffering in the United States, 1975-2013. In F. Maggino (Ed.), A life devoted to quality of life. Festchrift in Honor of Alex C. Michalos, pages 23-41 (p. 60). Springer. Social Indicators Research Series

Lee, B. J., \& Yoo, M. S. (2015). Family, school, and community correlates of children's subjective wellbeing: An international comparative study. Child Indicators Research, 8, 151-175. https://doi. org/10.1007/s12187-016-9373-3

Levin, K. A., Torsheim, T., Vollebergh, W., Richter, M., Davies, C. A., Schnohr, C. W. ... Currie, C. (2011). National income and income inequality, family affluence and life satisfaction among 13-year-old boys and girls: A multilevel study in 35 countries. Social Indicators Research, 104, 179-194. https:// doi.org/10.1007/s11205-010-9747-8

Main, G., Montserrat, C., Andresen, S., Bradshaw, J., \& Lee, B. J. (2019). Inequality, material well-being, and subjective well-being: Exploring associations for children across 15 diverse countries. Children and Youth Services Review, 97, 3-13. https://doi.org/10.1016/j.childyouth.2017.06.033

Metler, S. J., \& Busseri, M. A. (2017). Further evaluation of the tripartite structure of subjective wellbeing: Evidence from longitudinal and experimental studies. Journal of Personality, 85(2), 192-206. https://doi.org/10.1111/jopy.12233. Epub 2015 Dec 3

Newland, L.A., Giger, J.T., Lawler, M.J., Roh, S., Brockevelt, B.L. and Schweinle, A. (2019). Multilevel analysis of child and adolescent subjective well-being across 14 countries: Child- and country-level predictors. Child Development, 90, 395-413. https://doi.org/10.1111/cdev.13134

Ovaska, T., \& Takashima, R. (2006). Economic policy and the level of self-perceived well-being: An international comparison. Journal of Socio-Economics, 35, 308-325

Oyarzún, D., Casas, F., \& Alfaro, J. (2019). Family, school, and neighbourhood microsystems influence on children's life satisfaction in Chile. Child Indicators Research, 12, 1915-1933. https://doi. org/10.1007/s12187-018-9617-5

Rees, G., \& Main, G. (Eds.). (2015). Children's views on their lives and well-being in 15 countries: A report on the Children's Worlds survey, 2013-14. Children's Worlds Project (ISCWeB). http://www. isciweb.org/_Uploads/dbsAttachedFiles/ChildrensWorlds2015-FullReport-Final.pdf

Rees, G., Savahl, S., Lee, B. J., \& Casas, F. (Eds.). (2020). Children's views on their lives and well-being in 35 countries: A report on the Children's Worlds project, 2016-19. Jerusalem, Israel: Children's Worlds Project (ISCWeB). https://isciweb.org/wp-content/uploads/2020/07/Childrens-Worlds-Comparative-Report2020.pdf

Savahl, S., Casas, F., \& Adams, S. (2021). The structure of children's subjective well-being. Frontiers in Psychology. https://doi.org/10.3389/fpsyg.2021.650691

Schyns, P. (1998). Cross-national differences in happiness: Economic and cultural factors explored. Social Indicators Research, 43(1-2), 3-26. https://doi.org/10.1023/A:1006814424293

Schyns, P. (2002). Wealth of nations, individual income and life satisfaction in 42 countries: A multilevel approach. Social Indicators Research, 60(1-3), 5-40

Seligson, J. L., Huebner, E. S., \& Valois, R. F. (2003). Preliminary validation of the brief multidimensional students' life satisfaction scale (BMSLSS). Social Indicators Research, 61(2), 121-145. https://doi. org/10.1023/A:1021326822957 
Tamir, M., Schwartz, S. H., Cieciuch, J., Riediger, M., Torres, C., Scollon, C. ... Vishkin, A. (2016). Desired emotions across cultures: A value-based account. Journal of Personality and Social Psychology, 111(1), 67-82. https://doi.org/10.1037/pspp0000072

Wang, S., \& Fowler, P. J. (2019). Social cohesion, neighborhood collective efficacy, and adolescent subjective well-being in urban and rural Taiwan. American Journal of Community Psychology, 63(3-4), 499-510. https://doi.org/10.1002/ajcp.12324

Publisher's Note Springer Nature remains neutral with regard to jurisdictional claims in published maps and institutional affiliations.

\section{Authors and Affiliations}

\section{Ferran Casas $^{1} \cdot$ Mònica González-Carrasco ${ }^{1} \cdot$ Xavier Oriol $^{2} \cdot$ Sara Malo $^{2}$}

$\triangle$ Mònica González-Carrasco

monica.gonzalez@udg.edu

1 Doctoral Program on Education and Society, Faculty of Education and Social Sciences, Universidad Andrés Bello, Santiago, Chile

2 Research Institute on Quality of Life, University of Girona, Girona, Spain 